\title{
Heterologous Rhizobial Lipochitin Oligosaccharides and Chitin Oligomers Induce Cortical Cell Divisions in Red Clover Roots, Transformed with the Pea Lectin Gene
}

\author{
Clara L. Díaz, Herman P. Spaink, and Jan W. Kijne \\ Institute of Molecular Plant Sciences, Leiden University, Wassenaarseweg 64, 2333 AL Leiden, \\ The Netherlands \\ Accepted 15 November 1999.
}

\begin{abstract}
Division of cortical cells in roots of leguminous plants is triggered by lipochitin oligosaccharides (LCOs) secreted by the rhizobial microsymbiont. Previously, we have shown that presence of pea lectin in transgenic white clover hairy roots renders these roots susceptible to induction of root nodule formation by pea-specific rhizobia $(C$. $L$. Díaz, L. S. Melchers, P. J. J. Hooykaas, B. J. J. Lugtenberg, and J. W. Kijne, Nature 338:579-581, 1989). Here, we report that pea lectin-transformed red clover hairy roots form nodule primordium-like structures after inoculation with pea-, alfalfa-, and Lotus-specific rhizobia, which normally do not nodulate red clover. External application of a broad range of purified LCOs showed all of them to be active in induction of cortical cell divisions and cell expansion in a radial direction, resulting in formation of structures that resemble nodule primordia induced by clover-specific rhizobia. This activity was obvious in about $50 \%$ of the red clover plants carrying hairy roots transformed with the pea lectin gene. Also, chitopentaose, chitotetraose, chitotriose, and chitobiose were able to induce cortical cell divisions and cell expansion in a radial direction in transgenic roots, but not in control roots. Sugarbinding activity of pea lectin was essential for its effect. These results show that transformation of red clover roots with pea lectin results in a broadened response of legume root cortical cells to externally applied potentially mitogenic oligochitin signals.
\end{abstract}

Additional keywords: N-acylated GlcN, PSL, psl.

Soil bacteria from the genera Bradyrhizobium, Sinorhizobium, Mesorhizobium, and Azorhizobium, collectively referred to as rhizobia, induce formation of nitrogen-fixing nodules on the roots of leguminous plants. Some rhizobial strains nodulate a limited set of host plants, whereas other strains have a broader host range. Expression of rhizobial nodulation genes is induced by host plant flavonoids, resulting in synthesis and secretion of lipochitin oligosaccharides (LCOs). These signals specifically trigger a range of responses, including the forma-

Corresponding author: Clara L. Díaz; Telephone: +31 71527 4927; Fax: +31 71527 5088; E-mail: diaz@ rulbim.leidenuniv.nl tion of nodule primordia in the host plant root, which start as a loci of dividing cortical cells (Kijne 1992; Spaink 1996). Rhizobial LCOs have a common backbone of $\beta$-1,4-linked $N$ acetyl-D-glucosamine residues carrying an $\mathrm{N}$-linked fatty acyl chain at the nonreducing end. The length of the carbohydrate moiety and that of the acyl chain, the degree of saturation of the acyl chain, as well as substitutions of the reducing and nonreducing sugar residues, are characteristic of each rhizobial biovar or species. LCOs are primary determinants of host specificity in the Rhizobium-legume symbiosis (Spaink 1996; Promé and Demont 1996; Schultze and Kondorosi 1996). Specificity is assumed to be expressed via recognition, transport, and/or metabolization of LCOs.

Pea-specific rhizobia, $R$. leguminosarum bv. viciae, usually do not nodulate clover. However, pea-specific rhizobia can infect and induce formation of nodulelike structures and (a few) nodules on white clover roots after introduction of the pea lectin gene, psl (Díaz et al. 1989, 1995b). Similarly, transformation of Lotus corniculatus with soybean agglutinin (SBA) allowed the development of nodulelike structures after inoculation with Bradyrhizobium japonicum, which nodulates soybean and not Lotus spp. (Van Rhijn et al. 1998). Lectins are proteins with at least one noncatalytic sugar-binding domain. PSL (Pisum sativum lectin) and SBA belong to the family of legume lectins characterized by an essential Asn residue that binds the sugar ligand as well as an essential $\mathrm{Ca}^{+2}$ ion (Asn-Ca lectins; Kijne et al. 1997). In transgenic white clover roots, PSL appeared to be present on the tip of growing root hairs (the target cells of rhizobial infection) with one or both sugar-binding domains directed to the environment (Díaz et al. 1995a). These results suggested that the presence of PSL on clover root hairs enables a significant response to peaspecific LCOs.

The present paper addresses the specificity of the response of $p s l$-transgenic clover roots to LCOs. We took advantage of the fact that LCOs induce cortical cell divisions, which can be externally identified as a discrete root swelling appearing at the application area of LCOs (López-Lara et al. 1995). Because of the sporadic response of white clover to inoculation with pea-specific rhizobia (Díaz et al. 1989; Van Eijsden et al. 1995), and because red clover responds exclusively to cloverspecific rhizobia and LCOs, we used red clover rather than 
white clover as a test plant. The results show that, in red clover hairy roots transformed with the $p s l$ gene, cortical cell divisions were induced by various types of LCOs isolated from rhizobia that do not induce such a response in roots lacking the lectin gene. In addition, we show that externally applied chitin fragments induce mitogenic activity in psl-transgenic red clover roots.

\section{RESULTS}

\section{Root cortical cell divisions induced by rhizobia.}

As a control, we first inoculated the region of emerging root hairs of normal and red clover hairy roots with the homologous symbiont $R$. leguminosarum bv. trifolii ANU 843, and analyzed the roots for cell division activity. In the region concerned, both types of roots consist of an epidermis, three or four cortical cell layers, and a thin endodermis enclosing the central vascular tissues. In plants showing a quick mitotic response (about $20 \%$ of the plants), cell divisions started in a discrete number of elongated cells in the inner cortex, adjacent to the endodermis, 48 to $72 \mathrm{~h}$ after inoculation. Mitotic activity radiated to neighboring cortical cell layers and newly formed cells expanded. Longitudinal sections show that cell expansion occurs basically by elongation in radial direction. Induction of root cortical cell divisions did not require infection thread formation (Fig. 1F). At a later stage, cell expansion was more pronounced in the two outer cortical cell layers and in cells positioned laterally to a cluster of dividing cells (Fig. $1 G$ ). Dividing and expanding cells together form a nodule primordium, which can be externally identified as a swollen root area, 7 to 10 days after inoculation. In $70 \%$ of plants carrying transformed roots, Rhizobium-induced nodule primordia emerged as round, young nodules 12 to 14 days after inoculation (Fig. 1E). Within 3 weeks after inoculation, nodules appeared on other roots and in all inoculated plants. Nodulation phenomena with normal or hairy roots were indistinguishable from those in psl-transformed plants. Apparently, nodulation of hairy roots of red clover by clover-specific rhizobia is similar to the wild type situation, and introduction of the psl gene does not influence this process in the time period of experimentation. Uninoculated plants did not form nodules.

Inoculation with the pea symbiont $R$. leguminosarum bv. viciae yielded results similar to those obtained with white clover (Díaz et al. 1989, 1995b), in that $60 \%$ of red clover plants with hairy roots transformed with the psl gene showed root nodules and nodule primordia (Fig. 1J,L). This response was not observed when $R$. leguminosarum bv. viciae was inoculated on transgenic roots lacking the $p s l$ gene. Inoculation with the alfalfa symbiont $S$. meliloti or with the Lotus symbiont $M$. loti did not yield a nodulation response in psl-transformed plants. However, since this result could be caused by improper induction of nodulation genes by secreted red clover root flavonoids, we crossed plasmid pMP604 into these strains. This plasmid contains a nodD chimeric construct, which confers upon rhizobia the ability to constitutively produce LCOs (Spaink et al. 1989). Interestingly, about half of the psltransgenic plants inoculated with the induction-independent $S$. meliloti or $M$. loti responded by formation of root swellings resembling nodule primordia, which sometimes emerged to resemble nodules within 6 weeks after inoculation (Fig.1I,K). In contrast, plants with hairy roots without the psl gene and normal plants did not show such response. Taken together, these results strongly suggest that presence of the psl gene renders red clover roots susceptible to LCOs produced by heterologous rhizobia.

\section{Response to clover-specific LCOs.}

In order to test the susceptibility of red clover roots to purified LCOs, we first studied the response of normal red clover roots to application of LCOs isolated from R. leguminosarum bv. trifolii pMP3434, a strain that induces formation of nodule primordia within 8 days after inoculation (Bloemberg et al. 1995). These LCOs induced swellings on the roots of normal red clover plants within 2 weeks after application, as previously reported (Bloemberg et al. 1995). Root swellings, originating from extensive cortical cell divisions and radial cell expansion, were observed in about $70 \%$ of transformed red clover plants 2 weeks after application of $R$. leguminosarum bv. trifolii LCOs, regardless of the presence of the psl gene (Table 1). These structures appeared at the same site or at 1 to 3 cells distance from the applied sand particles. Cleared, transparent roots usually revealed one locus of dividing and expanded cells, without evidence of cell divisions induced in older or younger parts of the roots. Development of two or more loci was correlated with the distribution of coated sand particles around the point of application (see Figure 2B). Under our experimental conditions, the loci of divided and expanded cells did not develop into nodules. Longitudinal sections of these structures revealed developmental stages similar to those of nodule primordia triggered by inoculation with $R$. leguminosarum bv. trifolii bacteria (not shown).

In the response area, cell divisions in the pericycle, that precede formation of lateral roots (shown in Figure 1B and C), as well as emerging lateral roots (Fig. 1D) could be observed in $15 \%$ of the roots. Transformation with the psl gene followed by application of LCOs did not affect the frequency of lateral root initiation.

From these observations, we concluded that red clover hairy roots represent a suitable system to test whether presence of the $p s l$ gene affects the response of red clover roots to external application of heterologous LCOs and related compounds.

\section{Response to heterologous LCOs.}

We treated hairy roots of red clover, transformed with the psl gene, with LCOs produced by various rhizobia that do not nodulate normal or hairy roots not carrying the pea lectin gene. We positively scored plants showing root swellings at or near the site of application, which externally could not be distinguished from swellings induced by inoculation with $R$. leguminosarum bv. trifolii or by application of $R$. leguminosarum bv. trifolii LCOs, and which emerged on transformed roots, as judged from histochemical staining for reporter gene activity (Fig. 2B,C,I). Table 1 shows that introduction of the psl gene into red clover hairy roots allowed for induction of cortical cell divisions and radial cell expansion by heterologous LCOs in about $50 \%$ of the treated plants. This response could be triggered by LCOs containing chitin tetramers $(S$. meliloti and R. leguminosarum bv. viciae) or pentamers (all other LCOs used in this study). The type of fatty acid Nlinked to the sugar positioned at the nonreducing terminus appeared to be not critical since these LCOs carry acyl chains of 
different lengths and saturation (C16:2 in S. meliloti, C18:1 and C18:4 in R. leguminosarum bv. viciae, and C18:1 in $M$. loti LCOs). In addition, substitutions on carbon- 6 of the sugar residue at the reducing terminus ( $O$-sulfate group in $S$. meliloti, and 4-acetyl-L-fucose in M. loti LCOs) did not hinder induction of cortical cell divisions and radial cell expansion, nor did the 4-O-carbamoyl substitution at the nonreducing sugar of $M$. loti LCOs. The activities of the deacetylated LCOs (modified $R$. leguminosarum bv. viciae and wild-type $M$. loti LCOs) demonstrated that the $O$-acetyl group attached to the nonreducing sugar, such as in $R$. leguminosarum bv. trifolii, S. meliloti, and unmodified $R$. leguminosarum bv. viciae LCOs, is also not required for induction of cell divisions and cell expansion in radial direction.

In clear contrast, hairy roots of red clover transformed without the psl gene did not respond to application of heterologous LCOs (Table 1, Fig. 2E,F).

Sections of root swellings induced by $R$. leguminosarum bv. viciae and $S$. meliloti LCOs in psl-transformed roots revealed anatomical features that were similar to those of nodule primordia induced by $R$. leguminosarum bv. trifolii bacteria or LCOs, and that were typical of primordia of indeterminate nodules. In red clover roots, cell divisions in the pericycle occur soon after the onset of cortical cell divisions and cell expansion in a radial direction. As a result, the endodermis cannot be identified at the cell division site. This is shown in Figure $2 \mathrm{H}$ in a structure induced by $R$. leguminosarum bv. viciae LCOs, which represents the most advanced stage of development of mitotic activity and radial cell expansion triggered by homologous or heterologous LCOs. The area of mitotic activity induced by LCOs usually occupied a more extended area than the majority of cell division areas induced by $R$. leguminosarum bv. trifolii bacteria. However, nodule primordia induced by $R$. leguminosarum bv. trifolii in the neighborhood of already developing nodules were usually as extended as primordia induced after external application of LCOs, as shown in Figure 1E.

Some areas of cortical cell divisions induced by $M$. loti LCOs ( $M$. loti induces determinate nodules in Lotus) were shown to be quite similar to the ones triggered by the other LCOs (Fig. 2C). However, some root swellings resulted from cortical cell division and radial cell expansion in the outer or middle cortical cell layers. We could also observe loci of dividing subepidermal cells that appeared in combination with divided and expanded cells originating from inner cortical cell divisions (Fig. 2I).

\section{The oligochitin backbone of LCOs is sufficient for induction of a mitogenic response in psl-transformed roots.}

We tested the induction of cortical cell divisions by external application of chitin oligosaccharides and other carbohydrates (Table 2). Hairy roots transformed with the psl gene showed swellings after application of chitin fragments consisting of 5, 4,3 , or $2 \mathrm{~N}$-acetyl-glucosamine (GlcNAc) residues. This response was not observed in hairy roots of the control plants. Application of sand particles coated with $10^{-3} \mathrm{M}$ chitopentaose resulted in induction of cortical cell divisions and radial cell expansion in $70 \%$ of the treated plants transformed with psl. Smaller chitin fragments were less active, eliciting the response in about $40 \%$ of the plants. After application of sand particles coated with $10^{-7}$ or $10^{-9} \mathrm{M}$ chitopentaose, areas of cortical cell divisions and cell expansion could be observed in $30 \%$ of the psl-transformed plants (see Figure 2J), whereas $20 \%$ showed the same response when $10^{-5} \mathrm{M}$ tetraose was used. An additional $O$-acetyl group attached to the nonreducing residue of chitopentaose $\left(10^{-4} \mathrm{M}\right)$ did not affect the percentage of responding plants. Interestingly, inner cortical cell division limited to two or three cells was observed in three out of $20 \mathrm{psl}$-transformed roots, as a response to application of GlcNAc-coated sand particles. This response was not observed in any of the control roots. Application of sand particles coated with $\beta$-1,4-linked glucosamine or glucose oligomers at $10^{-3} \mathrm{M}$ failed to induce swellings or inner cortical cell divisions in psl-transformed and in control roots. These results show that the observed mitogenic activity is confined to compounds containing GlcNAc. This is consistent with the observation that $\mathrm{O}$-acetylated chitin oligosaccharides delivered by microtargeting, together with uridine, are able to induce cortical cell divisions in Vicia sativa roots (Schlaman et al. 1997). Apparently, the oligochitin backbone of LCOs is a mitogenic signal.

Fig. 1. Lateral root development and nodule induction by rhizobia in hairy roots of red clover. B, C, F, G, and $\mathbf{H}$, Longitudinal sections stained for fluorescence microscopy. A, High frequency of transformation of red clover, as judged from $\beta$-glucuronidase (GUS) activity assayed 4 weeks after transformation. Introduction of $p s l$ did not affect result. B, Early stage of lateral root development, presenting a locus of isodiametric proliferating cells (arrow) derived from pericycle. Arrangement of neighboring cortical cells is not (yet) disturbed. C, At a more advanced stage, outer layer (arrow) of lateral root primordium is already differentiated; neighboring cortical cells appear to be compressed and starting to divide. This root prim ordium cannot yet be noticed by external examination. D, The acuminate form of an emerging lateral root (arrow) contrasts with the extended, broad areas of response (arrowheads) appearing after application of mitogenic signals (in this case chitotetraose, coated onto sand particles that appear above arrowheads). E, Emerging nodule (EN) and extended nodule primordium (NP) on a red clover hairy root transformed with psl and 35S-GUS Int, 2 weeks after inoculation with Rhizobium leguminosarum bv. trifolii ANU 843. Cleared root shows GUS activity. F, Section of an early stage of nodule primordia induced by $R$. leguminosarum bv. trifolii ANU 843 in a root of wild-type red clover, showing predominance of cortical cell divisions in inner cortex and cell expansion in outer cortical cell layers. Arrow points to endodermis. G, A later stage of development of a nodule primordium induced by $R$. leguminosarum bv. trifolii ANU 843 in a red clover hairy root transformed with pBin19 35S-GUS Int. Endodermis has disappeared; cell divisions are also observed in outer cortical cell layers. H, Section through an emerging nodule induced by $R$. leguminosarum bv. trifolii ANU 843 in a root of wild-type red clover, showing bacteria (arrow) in infection zone. This stage of development corresponds with that of the emerging nodule in E. Root nodule initiation and development are similar in wild type and hairy roots of red clover. I, Root swellings (arrowheads) induced by Sinorhizobium meliloti pMP604 on a psl-transformed root, 4 weeks after inoculation. J, Emerging, nodulelike structures (arrowheads) 6 weeks after inoculation of red clover psl-transformed hairy roots with $R$. leguminosarum bv. viciae. K, Nodulelike structures (arrowheads) induced by nod-induction independent Mesorhizobium loti, 6 weeks after inoculation of psl-transformed hairy roots. L, Emerging, nodulelike structure induced by $R$. leguminosarum bv. viciae on a psl-transformed hairy root. Postfixation with $1 \% \mathrm{OsO}_{4}$ allowed for contrast of main root and lateral root primordia vascular bundles (arrows) and tissue of a nodulelike structure (arrowhead). Dehydration with ethanol cleared tissues. Bar = (A) $3.5 \mathrm{~mm} ;(\mathbf{B}, \mathbf{C}, \mathbf{F}, \mathbf{G}) 80 \mu \mathrm{m} ;(\mathbf{D}) 325 \mu \mathrm{m} ;(\mathbf{E}) 250 \mu \mathrm{m} ;(\mathbf{H}) 120 \mu \mathrm{m} ;(\mathbf{I}) 325 \mu \mathrm{m} ;(\mathbf{J}, \mathbf{K})$ $300 \mu \mathrm{m} ;(\mathbf{L}) 100 \mu \mathrm{m}$. 


\section{$\mathbf{N}$-acylated glucosamine induces cortical cell divisions.}

Table 2 shows that $55 \%$ of the plants transformed with $p s l$ presented swollen areas at the site of application of sand particles coated with $\mathrm{N}$-acylated glucosamine $(\mathrm{GlcN})$. Swellings resulted from cortical cell divisions and radial cell expansion, as shown in Figure 2K. Hairy roots of control plants (lacking $p s l$ ) did not show swellings. However, serial sectioning of the application area revealed that $60 \%$ of these hairy roots showed inner cortical cell divisions, apparently induced by $\mathrm{N}$-acylated GlcN . To test whether this mitogenic activity was related to the specific hormonal housekeeping of hairy roots, N-acylated GlcN was applied to the zone of emerging root hairs of wild-type red clover roots, $72 \mathrm{~h}$ after germination. Sixteen days later, none of these roots showed swellings. However, serial sectioning showed cortical cell divisions in 50\% of the roots (Fig. 2L), like those in similarly treated hairy roots. Transition from a few cor-
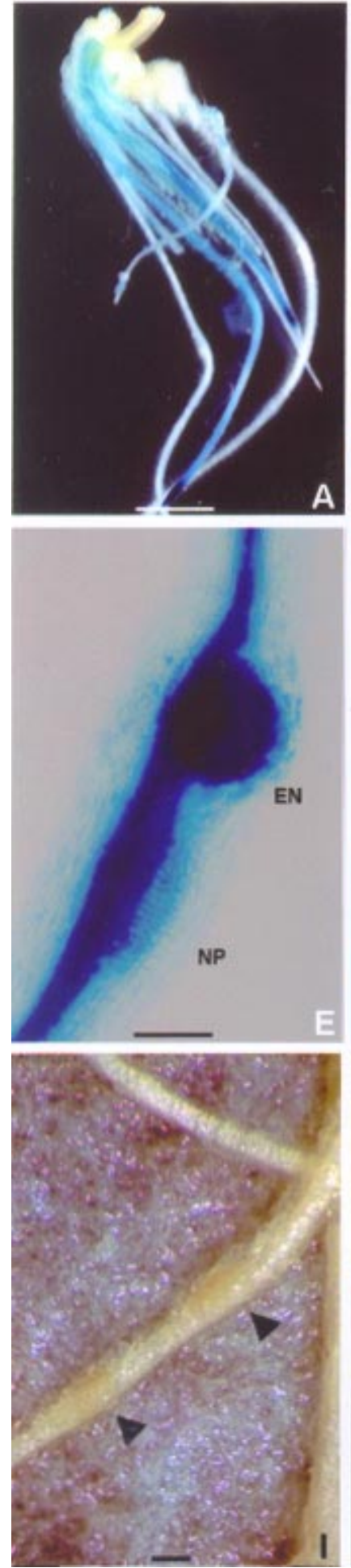
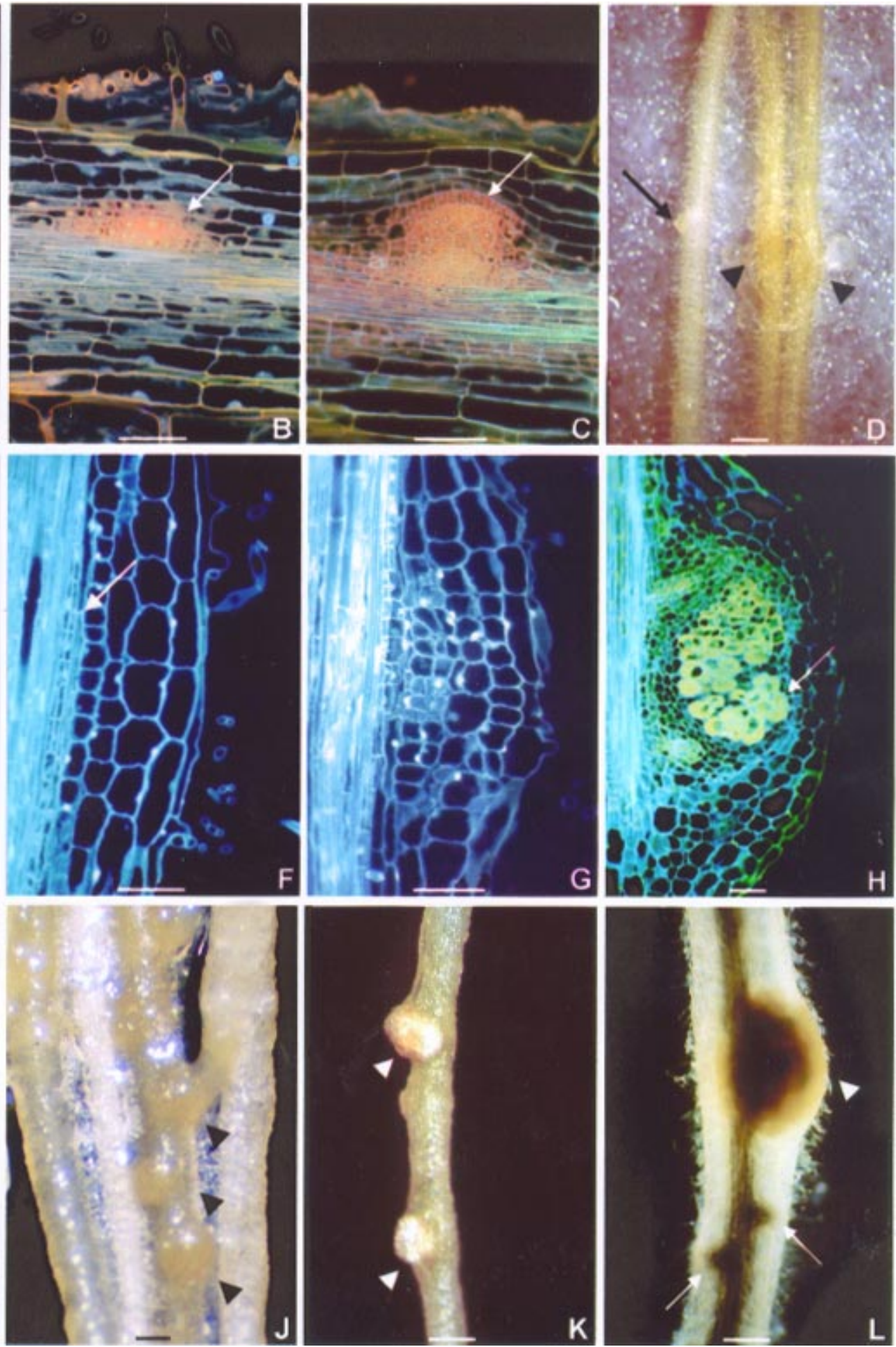
It should be noted that host legume roots do respond to LCOs carrying various host specificity determinants. For instance, Phaseolus vulgaris recognizes Azorhizobium caulinodans Nod factors with a variety of chemical substituents (Laeremans et al. 1999). LCOs isolated from B. japonicum, which are structurally related but not identical to $M$. loti LCOs, are able to induce formation of nodule primordia in about $50 \%$ of Lotus corniculatus plants (Van Rhijn et al. 1998). However, in the presence of soybean lectin, nodules rather than primordia were formed following inoculation with B. japonicum. A truncated LCO-type signal that has been shown to be able to trigger nodule initiation in Medicago sativa and white clover is N-acylated GlcN (Philip-Hollingsworth et al. 1997). With our experimental system, we could confirm that this signal molecule could induce inner cortical cell divisions in roots of wild-type red clover and in hairy roots lacking the $p s l$ gene. However, only serial sectioning of these roots could reveal such cell divisions. Transformation
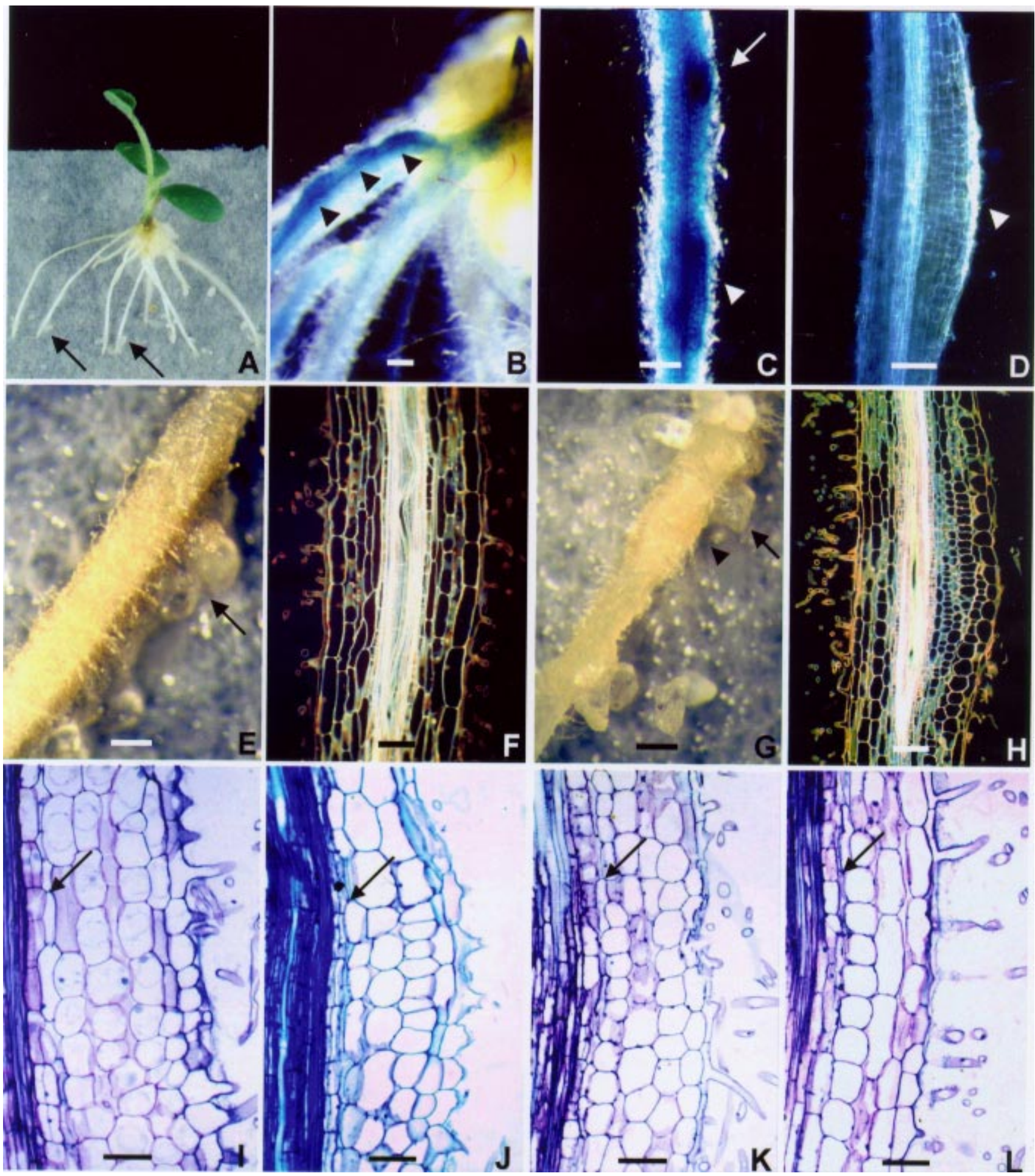
with psl enhanced the response to $\mathrm{N}$-acylated GlcN, to show more extensive areas of cell division and radial cell expansion. Moreover, the PSL-mediated response resulted in swellings resembling nodule primordia induced by inoculation with $R$. leguminosarum bv. trifolii that could be observed by external examination. These observations suggest that the competence of legume roots to respond to mitogenic signals can be improved by plant factors such as Asn-Ca root lectins. These legume lectins are widely used as mitogenic agents for lymphocytes and, in parallel with our results, the carbohydrate binding activity of these lectins is required for this effect (Mirkov and Chrispeels 1993). If lectins have a similar effect on certain plant cells, they could act in synergism with other mitogenic agents. However, it should be clear that the mitotic response needs to be triggered. Transgenic clover roots expressing the $p s l$ gene behave like normal roots in the absence of rhizobia or LCOs, as shown by examination of sections of the area of application of sand particles coated with the solvents used to solubilize LCOs.

Enhancement of the mitotic response induced by improper LCOs by Asn-Ca lectins such as PSL and soybean lectin leave the machinery controlling the response of transformed host plants to the homologous symbiont unaffected: nodules are formed in time and formation of nodule primordia is induced by purified LCOs in hairy roots of white and red clover (this work; Díaz et al. 1989) and in regenerated Lotus corniculatus plants (van Rhijn et al. 1998). In hairy roots of red clover, PSL is required for the mitogenic activity triggered by improper LCOs and chitin-related molecules. With exception of the response to $\mathrm{N}$-acylated $\mathrm{GlcN}$, sections of the area of application showed that cortical cells did not divide in hairy roots lacking the $p s l$ gene. This shows that the putatively altered hormonal balance of red clover hairy roots by itself does not make these roots susceptible to mitogens.

Acylation is not necessary for an external LCO-type signal to evoke a response in host plant roots. For example, chitopentaose is able to induce expression of the ENOD40 gene in

Table 2. Root swellings resulting from cortical cell divisions induced by chitin-related molecules

\begin{tabular}{|c|c|c|}
\hline \multirow[b]{2}{*}{ Carbohydrates $^{\mathrm{a}}$} & \multicolumn{2}{|c|}{ Plants exhibiting a response $(\%)$} \\
\hline & $\begin{array}{c}\text { Transformed } \\
\text { with psl and } 35 S \\
\text { GUS Int }\end{array}$ & $\begin{array}{l}\text { Transformed with } \\
\quad 35 S \text { GUS Int }\end{array}$ \\
\hline O-acetylated chitopentaose $\mathrm{c}^{\mathrm{c}}$ & 57.5 & 0.0 \\
\hline Chitopentaose & 70.0 & 0.0 \\
\hline Chitotretraose & 40.0 & 0.0 \\
\hline Chitotriose & 45.0 & 0.0 \\
\hline Chitobiose & 42.5 & 0.0 \\
\hline$N$-acetyl-glucosamine & 0.0 & 0.0 \\
\hline $\mathrm{N}$-acylated-glucosamine ${ }^{\mathrm{c}}$ & 55.0 & 0.0 \\
\hline Chitosan tetramer & 0.0 & 0.0 \\
\hline Cellopentaose & 0.0 & 0.0 \\
\hline
\end{tabular}

${ }^{a}$ Unless otherwise indicated, $10^{-3} \mathrm{M}$ oligosaccharides were used to coat $100 \mathrm{mg}$ of sterilized sand, representing a volume of $100 \mu \mathrm{l}$, enough for application to 30 to 40 plants (three to eight hairy roots per plant).

${ }^{b}$ Data represent average of two sets of transformation-application experiments, except for $\mathrm{N}$-acylated glucosamine, which was tested 3 times. A set consisted of 20 plants tranformed with psl and $35 \mathrm{~S} \mathrm{Gus} \mathrm{Int}$ and 20 plants transformed with $35 \mathrm{~S}$ Gus Int, respectively. Variation among plants showing a response fluctuated around 5\%.

${ }^{c}$ Concentration of O-acetylated chitopentaose and $\mathrm{N}$-acylated GlcN was estimated at $10^{-4} \mathrm{M}$. soybean roots (Minami et al. 1996). However, this expression is transient rather than persistent, and is not correlated with root nodule primordium formation. In our system, transformation with psl enlarged the response to chitin oligosaccharides to include root cortical cell division and expansion in a radial direction, resulting in structures that developed at the site of application and that resembled nodule primordia induced by $R$. leguminosarum bv. trifolii. These results provide additional evidence that decorations of LCOs are not principally required for mitogenic activity (Schlaman et al. 1997). In the rhizosphere, truncated LCO-type signals, including $\mathrm{N}$-acylated GlcN, could result from cleavage of rhizobial LCOs by plant enzymes (Staehelin et al. 1995; Schultze et al. 1998).

As a working hypothesis, we have proposed that Asn-Ca lectins stabilize legume root cells during elongation and differentiation (Kijne et al. 1997). Presence of a heterologous lectin may interfere with the function of the homologous lectin. Destabilized root cells may show an enhanced response or present a lower threshold for response to LCOs and chitin oligosaccharides. Our experiments suggest that root cortical cells, which undergo mitosis and elongation in a radial direction, can be the site of action of the heterologous lectin. Transcription of two lectin genes of Medicago trunculata in root nodule primordia elicited by $S$. meliloti or by purified LCOs supports the notion of involvement of root lectins in dividing cortical cells (Bauchrowitz et al. 1996).

Current models locate the putative LCO receptor at the root hair surface (for example, Felle et al. 1998). Goedhart et al. (1999) reported data that suggest that LCOs accumulate in the cell wall of root hair cells. If so, LCO receptors would share their location with Asn-Ca lectins in wild-type and in transformed roots (Díaz et al. 1995a; van Rhijn et al. 1998). Signal perception and/or signal response may be affected by the presence of a heterologous lectin in the vicinity of a receptor. Direct involvement of these lectins in LCO perception is unlikely, although PSL specifically binds glucose/mannose-type sugars, including GlcNAc (see, for example, Díaz et al. 1990). The $O$-acetyl group at the nonreducing sugar residue of several mitogenic molecules (Table 1) precludes binding to PSL (for a detailed discussion, see Kijne et al. 1994). In addition, extension of host specificity of Lotus corniculatus following transformation with soybean lectin, which binds specifically galactose and GalNAc (van Rhijn et al. 1998), argues for an indirect effect of Asn-Ca lectins in the perception mechanism leading to an enhanced response to mitogenic signals.

PSL in transgenic roots may also stimulate uptake of potential signals that normally remain extracellular. A positive correlation between mitogenic activity and uptake of LCOs and LCO-related molecules such as N-acylated GlcN in white clover root hairs has been reported (Philip-Hollingsworth et al. 1997). In red clover, improved uptake of N-acylated GlcN could explain the enhanced response of psl-transformed hairy roots to this molecule, as reported in Table 2.

Presence of PSL in clover roots may additionally facilitate endocytotic root hair infection by pea rhizobia, to enable infection thread formation (Díaz et al. 1989; for a recent discussion of a role of legume lectins in root hair infection, see Hirsch 1999). Since the presence of soybean lectin in transgenic $L$. corniculatus plants appeared to stimulate attachment of soybean rhizobia to the root hairs, Van Rhijn et al. (1998) explain their results by assuming that accumulation of brady- 
rhizobia caused a high concentration of heterologous LCOs at the root hair tips with an enhanced nodulation response as a result. Dose-response effects of heterologous (and homologous) lectins on LCO activity remain to be studied.

\section{MATERIALS AND METHODS}

\section{Plant transformation.}

Hairy roots were induced by Agrobacterium rhizogenes LBA 1334 on the stems of 4-day-old Trifolium pratensis L. (red clover; Kieft Zaden, Blokker, The Netherlands), according to the protocol developed for white clover (Díaz et al. 1989). For production of control roots, strain LBA1334 carried the modified $\beta$-glucuronidase (GUS) gene in the binary vector pBin19 (pBIN19 35S GUS Int; Vancanneyt et al. 1990). For production of $p s l$-transgenic roots, the reporter gene was cloned as a HindIII fragment into pBin19 psl (Díaz et al. 1989), resulting in vector pBin19 psl-35S GUS Int. Roots emerged within 1 week in $95 \%$ of the transformed plants. Removal of the primary root immediately after transformation brings about a synchronization of root emergence, as already reported for white clover (Díaz et al. 1989).

To test whether a lectin-mediated response required carbohydrate-binding activity of PSL, red clover plants were transformed with a psl mutant (PSL N125D) that does not bind sugars (Van Eijsden et al.1992).

\section{Rhizobia, LCOs, and carbohydrates used.}

The following rhizobial strains were used in this study: $R$. leguminosarum bv. trifolii ANU843 (Rolfe et al. 1980), $R$. leguminosarum bv. viciae 248 (Josey et al. 1979), Mesorhizobium loti E1R, M. loti E1R pMP604 (both M. loti strains described by López-Lara et al. 1995), Sinorhizobium meliloti 2011 (Faucher et al. 1988), and S. meliloti 2011 pMP604 (this work). Plasmid pMP604 confers constitutive expression of nod genes (Spaink et al. 1989). Red clover hairy roots were inoculated 8 to 10 days after transformation on the zone of emerging root hairs (Díaz et al. 1995b).

Isolation of LCOs from $R$. leguminosarum bv. trifolii pMP3434 has been described in Bloemberg et al. (1995). The $\mathrm{O}$-acetylated pentasaccharide and tetrasaccharide LCO fractions, carrying a C18:4 or C18:1 fatty acyl moiety from $R$. leguminosarum bv. viciae, were prepared as described before (Spaink et al. 1991). Deacetylation of this compound to obtain $R$. leguminosarum bv. viciae $\mathrm{V}$ (C18:1) was performed as described by Bloemberg et al. (1995). LCOs from M. loti E1R pMP283 were prepared as described by López-Lara et al. (1995). Each LCO was dissolved in 60:40 acetonitrile: $\mathrm{H}_{2} \mathrm{O} . S$. meliloti IV (C16,2, Ac, S) LCO was a kind gift of M. Schultze and was dissolved in $2 \mathrm{mM} \beta$-cyclodextrin (Sigma-Aldrich Chemie, Steinheim, Germany).

Chitin oligomers ( $\beta$-1,4-linked GlcNAc residues), GlcNAc, chitosan tetramer ( $\beta$-1,4-linked D-GlcN residues), and cellopentaose ( $\beta$-1,4-linked D-Glc residues) were purchased from Seikagaku (Tokyo). Aqueous stocks were diluted in 40:60 acetonitrile: $\mathrm{H}_{2} \mathrm{O}$ to the desired concentration. O-acetylated chitopentaose was obtained as described by Bloemberg et al. (1994). $N$-steroyl-glucosamine ( $\mathrm{N}$-acylated $\mathrm{GlcN})$ was prepared by acylation of GlcN with thiazolidine-2-thione active esters as described previously by Azéma et al. (1995), and was dissolved in methanol:chloroform: $\mathrm{H}_{2} \mathrm{O}$ 50:40:10. Sand particles were coated with LCOs and chitin oligomers as described previously (López-Lara et al. 1995).

\section{External application of LCOs and related carbohydrates.}

Twelve days after transformation, rooted red clover seedlings were transferred to plates containing solidified plant medium supplemented with $0.75 \mathrm{mM} \mathrm{Ca}\left(\mathrm{NO}_{3}\right)_{2}$, a condition allowing efficient nodulation (Díaz et al. 1995b). To ensure the presence of undamaged root tips and newly formed root hairs, application of sand particles coated with rhizobial LCOs and related carbohydrates on the zone of emerging root hairs was performed $48 \mathrm{~h}$ after transfer (López-Lara et al. 1995; Fig. 2A). A given compound was applied to 20 plants carrying roots transformed with psl-35S GUS Int and to 20 control plants with roots transformed with $35 S$ GUS Int. Usually, we tested six compounds per experiment. In each experiment, LCOs isolated from $R$. leguminosarum bv. trifolii or from $R$. leguminosarum bv. viciae were included as controls. To test the specificity of the reaction triggered by the applied compounds, we treated a set of plants with sand particles coated with the solvents used to solubilize LCOs and other carbohydrates. Induction of hairy roots, transfer to fresh growth plates, and application of coated sand particles were performed in a sterile hood. Plates were sealed after treatment of the plants and placed in growth trays, as described previously (Díaz et al. 1995b).

\section{Transformation efficiency.}

Transformation efficiency was assayed at the moment of application of sand particles or before evaluation of the putative mitogenic activity of applied compounds by determining the activity of the reporter enzyme with use of the substrate 5bromo-4-chloro-3-indolyl-D-glucuronide-cyclohexylammonium salt (Bauchrowitz et al. 1996). We observed blue staining in at least half of the number of roots, for $85 \%$ of the plants transformed with the control or with the psl-containing vector (Fig. 1A). The activity of the reporter gene showed that introduction of the lectin gene does not affect the frequency of transformation and that, in this system, selection pressure is not required to achieve a reasonably high efficiency of transformation.

\section{Biological activity.}

Roots were examined with a Wild M3Z binocular microscope (Heerbrugg, Switzerland) 14 to 16 days after application of sand particles coated with LCOs or related carbohydrates. Plants showing extended swellings, resembling nodule primordia, were scored as positive. These swellings appeared at the position of or very close to applied sand particles and were easily distinguished from acuminate emerging lateral roots (see Figure 1D). Applications were disclosed after scoring all plants used in the experiment (usually 240 plants). For further analysis, root systems were cleared with lactochlorophenol (Beeckman and Engler 1994) or assayed for the activity of the reporter enzyme. For detailed microscopical examination, pieces of root, about $0.5 \mathrm{~cm}$ in length and with the application area in the middle, were excised and fixed for $2 \mathrm{~h}$ with $2 \%$ paraformaldehyde and $1 \%$ glutaraldehyde. Root pieces were stepwise dehydrated, infiltrated, and embedded in Historesin (Leica Instruments, Heidelberg, Germany). Serial longitudinal sections ( $5 \mu \mathrm{m}$ in thickness) were stained for fluorescence microscopy (Dudley et al. 1987), or with $1 \%$ basic toluidine blue for light microscopy. Per applied compound, sec- 
tioning of the response area was performed on $25 \%$ of control plants with roots transformed with $35 S$ GUS Int and on 10 to $15 \%$ of plants with roots transformed with psl and $35 S$ GUS Int.

Sections stained for fluorescent microscopy were examined with a Leitz Diaplan microscope with a HBO 100W lamp, and an A filter block (BP 340-380, LP 430). Photographs were taken with Kodak 64T and Ektachrome 400 films, respectively. Films were commercially developed and printed.

\section{ACKNOWLEDGMENTS}

H. P. S. was supported by a pioneer grant from The Netherlands Organisation for Scientific Research (NWO) and a TMR grant for the European Union (ERBFMRXCT 980243)

\section{LITERATURE CITED}

Azéma, J., Chebli, C., Bon, M., Rico-Lattes, I., and Lattes, A. 1995. New surfactants with sugar-based polar heads derived from bile acid: the $N$-ursocholyl-D-glucosamine and $N$-dehydrocholyl-D-glucosamine. J. Carbohydr. Chem. 14:805-817.

Bauchrowitz, M., Barker, D. G., and Truchet, G. 1996. Lectin genes are expressed throughout root nodule development and during nitrogen fixation in the Rhizobium-Medicago symbiosis. Plant J. 9:31-43.

Beeckman, T., and Engler, G. 1994. An easy technique for the clearing of histochemically stained plant tissue. Plant Mol. Biol. Rep. 12:37-42.

Bloemberg, G. V., Kamst, E., Harteveld, M., Van der Drift, K. M. G. M., Haverkamp, J., Thomas-Oates, J. E., Lugtenberg, B. J. J., and Spaink, H. P. 1995. A certain domain of Rhizobium nodE protein mediates host specificity by determining the hydrophobicity of fatty acyl moieties of nodulation factors. Mol. Microbiol.16:1123-1136.

Bloemberg, G. V., Thomas-Oates, J. E., Lugtenberg, B. J. J., and Spaink, H. P. 1994. Nodulation protein NodL of Rhizobium leguminosarum Oacetylates lipo-oligosaccharides, chitin fragments and $\mathrm{N}$-acetylglucosamine in vitro. Mol. Microbiol. 11:793-804.

Díaz, C. L., Hosselet, M., Logman, G. J. J., van Driessche, E., Lugtenberg, B. J. J., and Kijne, J. W. 1990. Distribution of glucose/mannose specific isolectins in pea (Pisum sativum) seedlings. Planta 181:451-461.

Díaz, C. L., Logman, T. J. J., Stam, H. C., and Kijne, J. W. 1995a. Sugar-binding activity of pea lectin expressed in white clover hairy roots. Plant Physiol. 109:1197-1177.

Díaz, C. L., Melchers, L. S., Hooykaas, P. J. J., Lugtenberg, B. J. J., and Kijne, J. W. 1989. Root lectin as a determinant of host-plant specificity in the Rhizobium-legume symbiosis. Nature 338:579-581.

Díaz, C. L., Spaink, H. P., Wijffelman, C. A., and Kijne, J. W. 1995 b. Genomic requirements of Rhizobium for nodulation of white clover hairy roots transformed with the pea lectin gene. Mol. Plant-Microbe Interact. 8:348-356.

Dudley, M. E., Jacobs, T. W., and Long, S. R. 1987. Microscopic studies of cell divisions induced in alfalfa roots by Rhizobium meliloti. Planta 171:289-301.

Faucher, C., Maillet, F., Vasse, J., Rosenberg, C., van Brussel, A. A. N., Truchet, G., and Dénarié, J. 1988. Rhizobium meliloti host range $n o d H$ determines production of an alfalfa-specific extracellular signal. J. Bacteriol. 170:5489-5499.

Felle, H. H., Kondorosi, É., Kondorosi, Á., and Schultze, M. 1998. The role of ion fluxes in nod factor signalling in Medicago sativa. Plant $\mathrm{J}$. 13:455-463.

Goedhart, J., Röhrig, H., Hink, M. A., van Hoek, A., Visser, A. W. G., Bisseling, T., and Gadella, T. W. J., Jr. 1999. Nod factors integrate spontaneously in biomembranes and transfer rapidly between membranes and to root hairs, but transbilayer flip-flop does not occur. Biochemistry 38:10898-10907.

Hirsch, A. M. 1999. Role of lectins (and rhizobial exopolysaccharides) in legume nodulation. Curr. Opin. Plant Biol. 2:320-326.

Josey, D. P., Beynon, J. L., Johnston, A. W., B., and Beringer, J. E. 1979. Strain identification in Rhizobium using intrinsic antibiotic resistance. J. Appl. Microbiol. 46:343-350.

Kijne, J. W. 1992. The Rhizobium infection process. Pages 349-398 in: Biological Nitrogen Fixation. G. Stacey and R. H. Burris, eds. Chapman and Hall, New York.
Kijne, J., Bauchrowitz, M. and Díaz, C. L. D. 1997. Root lectins and Rhizobia. Plant Physiology 115:869-873.

Kijne, J. W., Díaz, C. L., Van Eijsden, R. Booij, P., Demel, R., van Workum, W., Wijfelman, C., Spaink, H., Lugtenberg, B., and de Pater, S. 1994. Lectin and Nod factors in Rhizobium-legume symbiosis. Pages 106-110 in: Proc. Eur. Nitrogen Fixation Conf., 1st. G. B. Kiss and G. Endre, eds. Officina Press, Szeged, Hungary.

Laeremans, T., Snoeck, C., Manën, J., Verreth, C., Martínez-Romero, E., Promé, J.-C., and Vanderleyden, J. 1999. Phaseolus vulgaris recognizes Azorhizobium caulinodans Nod factors with a variety of chemical substituents. Mol. Plant-Microbe Interact. 12:820-824.

López-Lara, I. M., van den Berg, J. D. J., Thomas-Oates, J. E., Glushka, J., Lugtenberg, B. J. J., and Spaink, H. P. 1995. Structural identification of the lipo-chitin oligosaccharide nodulation signals of Rhizobium loti. Mol. Microbiol. 15:627-638.

Minami, E., Kouchi, H., Cohn, J. R., Ogawa, T., and Stacey, G. 1996. Expression of the early nodulin, ENOD40, in soybean roots in response to various lipo-chitin signal molecules. Plant J. 10:23-32.

Mirkov, T. E., and Chrispeels, M. J. 1993. Mutation of Ans128 to Asp of Phaseolus vulgaris leucoagglutinin (PHA-L) eliminates carbohydratebinding and biological activity. Glycobiology 3:581-587.

Philip-Hollingsworth, S., Dazzo, F. B., and Hollingsworth, R. I. 1997. Structural requirements of Rhizobium chitolipooligosaccharides for uptake and bioactivity in legume roots as revealed by synthetic analogs and fluorescent probes. J. Lipid Res. 38:1229-1241.

Promé, J.-C., and Demont, T. 1996. Nodulation factors. Pages 272-307 in: Plant-Microbe Interactions, Vol. 1. G. Stacey and N. T. Keen, eds. Chapman and Hall, New York.

Rolfe, B. G., Gresshoff, P. M., and Shine, J. 1980. Rapid screening method for symbiotic mutants of Rhizobium leguminosarum biovar trifolii on white clover plants. Plant Sci. Lett. 19:277-284.

Schlaman, H. R. M., Gisel, A. A., Quaedvlieg, N. E. M., Bloemberg, G. V., Lugtenberg, B. J. J., Kijne, J. W., Potrykus, I., Spaink, H. P., and Sautter, C. 1997. Chitin oligosaccharides can induce cortical cell division in roots of Vicia sativa when delivered by ballistic microtargeting. Development 124:4887-4895.

Schultze, M., and Kondorosi, Á. 1996. The role of Nod signal structures in the determination of host specificity in the Rhizobium-legume symbiosis. World J. Microbiol. Biotechnol. 12:137-149.

Schultze, M., Staehelin, C., Brunner, F., Genete, I., Legrand, M., Fritig, B., Kondorosi, É., and Kondorosi, Á. 1998. Plant chitinase/lysozyme isoforms show distinct substrate specificity and cleavage site preference towards lipochooligosaccharides Nod signals. Plant J. 16:571-580.

Spaink, H. P. 1996. Regulation of plant morphogenesis by lipo-chitin oligosaccharides. Crit. Rev. Plant Sci. 15:559-582.

Spaink, H. P., Sheeley, D. M., Van Brussel, A. A. N., Glushka, J., York, W. S., Tak, T., Geiger, O., Kennedy, E. P., Reinhold, V. N., and Lugtenberg, B. J. J. 1991. A novel highly unsaturated fatty acid moiety of lipo-oligosaccharide signals determines host-specificity of $R h i$ zobium. Nature 354:125-130.

Spaink, H. P., Wijffelman, C. A., Okker, R. J. H., and Lugtenberg, B. J. J. 1989. Localization of functional regions of the Rhizobium nodD product using hybrid nodD genes. Plant Mol. Biol. 12:59-73.

Staehelin, C., Schultze, M., Kondorosi, É., and Kondorosi, Á. 1995. Lipo-chitooligosaccharide nodulation signals from Rhizobium meliloti induce their rapid degradation by the host plants alfalfa. Plant Physiol. 108:1607-1614.

Vancanneyt, G., Schmidt, R., O'Connor-Sanchez, A., Willmitzer, L., and Rocha-Sosa, M. 1990. Construction of an intron-containing marker gene: Splicing of the intron in transgenic plants and its use in monitoring early events in Agrobacterium-mediated plant transformation. Mol. Gen. Genet. 220:245-250.

Van Eijsden, R. R., Díaz, C. L., de Pater, B. S., and Kijne, J. W. 1995. Sugar-binding activity of pea (Pisum sativum) lectin is essential for heterologous infection of transgenic white clover hairy roots by $R h i-$ zobium leguminosarum biovar viciae. Plant Mol. Biol. 29:431-439.

Van Eijsden, R. R., Hoedemaeker, P. J., Díaz, C. L., Lugtenberg, B. J. J., de Pater, B. S., and Kijne, J. W. 1992. Mutational analysis of pea lectin. Replacement of the Asn125 by Asp in the monosaccharidebinding site eliminates mannose/glucose-binding activity. Plant Mol. Biol. 20:1049-1058.

Van Rhijn, P., Goldberg, R., and Hirsch, A. 1998. Lotus corniculatus nodulation specificity is changed by the presence of a soybean lectin gene. Plant Cell 10:1233-1249. 